\title{
Qualidade e Percepção do ambiente construído na Saúde mental de Médicos Residentes
}

\author{
SOUZA, Ellen Priscila Nunes de ${ }^{1}$ \\ PINA, Silvia Aparecida Mikami Gonçalves² \\ LABAKI, Lucila Chebel ${ }^{3}$ \\ GRASSI-KASSISSE, Dora Maria ${ }^{4}$ \\ CARDOSO, Tânia Aparecida Marchiori de Oliveira ${ }^{5}$ \\ SOUZA, Elisabete Abib Pedroso 6
}

1UNIFAVIP. Departamento de Arquitetura e Urbanismo. Caruaru/PE. Brasil UNIFBV. Departamento de Arquitetura e Urbanismo. Recife/PE. Brasil

E-mail: ellensouza.arq@gmail.com 2UNICAMP. Faculdade de Engenharia Civil, Arquitetura e Urbanismo. Campinas/SP. Brasil.

E-mail: smikami@fec.unicamp.br ${ }^{3}$ UNICAMP. Faculdade de Engenharia Civil, Arquitetura e Urbanismo. Campinas/SP. Brasil. E-mail: lucila@fec.unicamp.br ${ }^{4}$ UNICAMP. Instituto de Biologia. Campinas/SP. Brasil. E-mail: doramgk@g.unicamp.br 5UNICAMP. Faculdade de Ciências Médicas. Campinas/SP. Brasil. E-mail: taniamoc@uol.com.br 6UNICAMP. Faculdade de Ciências Médicas. Campinas/SP. Brasil.

E-mail: souzaeap@yahoo.com.br 


\section{Resumo}

Esta pesquisa discutirá a relação entre qualidade do ambiente construído com sistemas de iluminação e térmica estritamente artificiais e a saúde mental de médicos residentes do setor de Imaginologia, o qual exige condições ambientais específicas. Para verificar esta correlação foram avaliados o ambiente (aferindo suas variáveis), a percepção ambiental (aplicação de questionário específico) e avaliação psicológica determinando a existência e o grau de doenças como o estresse, ansiedade e depressão. Concluiu-se que dos três grupos de residência médica, os do primeiro ano sofreram influência tanto do desgaste já esperado quanto daquele provocado pelo ambiente; os do segundo ano demonstraram o desgaste profissional da residência médica deste período, mas já adaptação quanto ao meio; e os do terceiro ano apresentaram valores dentro do esperado para a atividade desenvolvida. Também foram identificados baixos índices de iluminância e temperatura, valores necessários à realização das atividades no setor da Imaginologia. Assim, acresceram-se ao estado-da-arte e à coleção de dados já existente informações sobre a influência do ambiente controlado artificialmente na percepção dos usuários, contribuindo para o desenvolvimento de recomendações visando a qualidade do ambiente hospitalar.

Palavras-Chave: Qualidade do ambiente construído; Saúde mental; Médico residente; Setor da Imaginologia.

\section{Abstract}

This research will discuss the relationship between the quality of the built environment, with only artificial systems (lighting and heat control), and resident doctors' mental health in a Radiology department, which has specific building design requirements. To establish this correlation the Radiology Departments' environment was evaluated (measuring variables of the built environment), environmental perception (with the application of a specific questionnaire) and psychological evaluation identifying the existence of and the level of mental illness such as stress, anxiety and depression. It was concluded that among the three resident doctors' groups, the students from the first group suffered expected psychological effects associated with the built environment; the ones from the second group demonstrated psychological effects typical of resident doctors' but have adapted to the built environment; and the students from the third group demonstrated values within the expected range for the activities performed. We also identified low illuminance and temperature, necessary to the activities. Thus, this research also added to the state-of-art and database, new information about the environment's influence on users' perception, fomenting to a development of recommendations aiming the hospital environment quality.

Key-Words: Quality of the built environment; Health psychology; Resident doctor; Imaging Sector. 


\section{Introdução}

Os edifícios têm implicações diversas nas qualidades de vida e de trabalho dos seres humanos. Os usuários e suas necessidades demandam ampla compreensão quanto à sua satisfação e à hierarquização das demandas em relação à qualidade do ambiente construído. Tal qualidade afeta a percepção e o comportamento de seus usuários.

Segundo Guzowski (1999), as pessoas se sentem saudáveis mediante o atendimento de aspectos de cunho qualitativo das necessidades físicas e psicológicas do corpo quanto do espírito e da mente. Todos os edifícios possuem características físicas, químicas e biológicas que podem afetar a saúde psicológica e fisiológica dos seus ocupantes (BREVIGLIERO et al., 2006; SASSI, 2006). Assim, a promoção da qualidade em saúde deve contar com ambientes onde diversos fatores devem ser considerados e trabalhados corretamente. A atenção a esses fatores e características influencia diretamente a percepção ambiental. Percepção esta entendida como resultante do processamento dos estímulos recebidos pelos sentidos, suscitando significado baseado em experiências anteriores (CARLSON, 2002; IIDA, 2005). Quando considerado o ambiente arquitetônico, as variáveis espaciais induzem em maior ou menor grau o ritmo biológico e o estado psicológico de seus usuários, alterando também a qualidade de vida destes. São insuficientes estudos que lidem com aqueles ritmo e estado, bem como suas interações com as características do ambiente hospitalar.

Desta forma, esta pesquisa verificou a influência das variáveis ambientais artificias do ambiente construído hospitalar na saúde psicológica de médicos residentes do Setor da Imaginologia do Hospital de Clínicas de Campinas/SP/Brasil de acordo com o nível de residência e por meio de perfilamento e avaliações do ambiente (sistema luminotécnico e térmico) e psicológica (ansiedade, depressão, estresse e sono), devido à associação entre as condições do ambiente de trabalho, eficiência profissional e qualidade de vida pessoal.

A seleção do espaço hospitalar para o estudo em questão traduziu a contradição existente no Brasil entre o espaço de cura e o espaço como provedor de saúde daqueles que nele trabalham. Muitos hospitais públicos brasileiros retratam uma realidade decadente com relação ao tratamento da edificação e cuidado do ambiente. $\mathrm{E}$ a isto se é somado os espaços onde a equipe de funcionários de saúde se apoia antes e depois da realização de procedimentos, onde exames e diagnósticos que orientam as intervenções e tratamentos são elaborados.

Contribuiu-se assim com o estado-da-arte, acrescendo na coleção de dados informações sobre a influência do ambiente sem contato com o meio externo na percepção, saúde psicológica e qualidade de vida dos usuários, auxiliando no desenvolvimento de diretrizes que guiem novos projetos arquitetônicos hospitalares.

\section{Metodologia}

\subsection{Avaliação das variáveis ambientais}

A avaliação consistiu na aferição in loco por instrumentais adequados das seguintes variáveis ambientais: iluminância (lux), temperatura $\left({ }^{\circ} \mathrm{C}\right)$, temperatura radiante $\left({ }^{\circ} \mathrm{C}\right)$, umidade relativa (\%) e velocidade do ar $(\mathrm{m} / \mathrm{s})$. Ela ocorreu em dois momentos específicos.

No primeiro momento verificou-se a iluminância do sistema de iluminação artificial geral dos principais ambientes do setor de Imaginologia. Utilizou-se o método de malha da NBR ISO/CIE 8995:1 Iluminação de ambientes de trabalho Parte 1: Interior (ABNT, 2013). Além dos pontos obtidos por norma, outros pontos foram incluídos para melhor composição da curva isolux. A aferição ocorreu na altura de $0,75 \mathrm{~m}$ (altura do plano de trabalho padrão), em condições reais de uso do ambiente. $\mathrm{O}$ instrumento utilizado foi o luxímetro digital modelo MLM-1010 da Minipa. Os valores aferidos foram comparados com os fornecidos pela NBR ISO/CIE 8995:1 (ABNT, 2013) de acordo com a atividade a ser desenvolvida.

No segundo momento aferiu-se o ambiente térmico (temperatura, temperatura radiante, umidade relativa e velocidade do vento). Para efeito de valores de base, as mínimas e máximas tanto da temperatura quanto da UR foram tomadas da NR 17 (ABNT, 2007): entre $20{ }^{\circ} \mathrm{C}$ e $23 \stackrel{\circ}{\circ} \mathrm{C}$ e entre $30 \%$ e 70 $\%$, respectivamente, e velocidade do ar $\leq 0,75 \mathrm{~m} / \mathrm{s}$. Usaram-se os seguintes instrumentos: i. dataLoggers HOBO U-12 da OnSet e TESTO para medições de temperatura e umidade relativa; ii. anemômetro 
digital de fio quente Testo 405 - V1, faixas de medição entre 0 a $5 \mathrm{~m} / \mathrm{s}$ de -20 a $0{ }^{\circ} \mathrm{C}$ e $10 \mathrm{~m} / \mathrm{s}$ de 0 $\mathrm{a}+50{ }^{\circ} \mathrm{C}$, precisão: $\pm 5 \%$ de velocidade média \pm 0.10 $\mathrm{m} / \mathrm{s}$ (até $2 \mathrm{~m} / \mathrm{s}) ; \pm 5 \%$ de velocidade média $\pm 0.3 \mathrm{~m} / \mathrm{s}$ (mais de $2 \mathrm{~m} / \mathrm{s}$ ); $\pm 0.5{ }^{\circ} \mathrm{C}$ temperatura; usado para medir a velocidade do vento, sem registro; iii. registrador Testo 175-H1, faixa de medição entre 0 a $100 \%$ de UR e -10 a $50 \stackrel{\circ}{\circ}$ de temperatura, precisão entre $\pm 3 \%$ na umidade e $\pm 0,5 \circ \mathrm{C}$ na temperatura, usado para aferir a temperatura do ar e a umidade relativa; e iv. registrador Testo 175-T2 com sonda externa de temperatura do ar Testo 06131712 e globo cinza (composto por bola oficial de tênis de mesa pintada com tinta azul burguês da Coral), faixa de medição entre -35 a 70 ○C (canal interno) e -40 a $120 \stackrel{\circ}{ } \mathrm{C}$ (canal externo/globo), precisão $\pm 0,5 \circ \mathrm{C}$ (canal interno) e $\pm 0,3 \stackrel{\circ}{\circ}$ (canal externo/globo). Os pontos aferidos para cada variável nos ambientes foram definidos pela norma ISO/DIS 7726 - Ambientes Térmicos - Instrumentos e Métodos para medições das quantidades físicas (ISO, 1996).

\subsection{Avaliação da percepção ambiental}

Utilizou-se e organizou-se questionário sistematizado e estruturado a partir dos objetivos e questionamentos da pesquisa acerca da percepção ambiental, conferindo divisão em quatro blocos: iluminação; térmica; acústica; e espaço e mobiliário. Todos esses com respostas múltipla escolha (sim/não) e livre (perguntas abertas).

O questionamento referente à percepção visual tomou como base modelos já usados pela área da iluminação, como Baker e Steemers (2002), Zumtobel (2008), Zumtobel (2010) e o framework conceitual proposto por Boyce (2006). Foram questionados através de múltipla escolha (sim/não): as condições e características do sistema de iluminação no local de execução das atividades; as características do projeto de iluminação; e a opinião dos usuários sobre iluminação geral. As perguntas abertas solicitaram as queixas e ideias para melhorar a iluminação no espaço de trabalho.

A avaliação de percepção térmica utilizou questionários feitos a partir de arquétipos empregados por área específica, adaptando questionamentos colocados por Batiz e Goedert (2006), seguindo as especificações da norma ISO 10551 - Ergonomics of the thermal environment Assessment of the influence of the thermal environment using subjective judgement scales (ISO, 1995). Também se empregou o critério de insatisfação desenvolvido por Fanger (1970): \pm 2 e \pm 3 (escala de Likert). Foram arguidos: o tipo de vestimenta usado no momento do questionário e preferências ambientais térmicas. Além das perguntas abertas que solicitaram as queixas e ideias para melhoria térmica no ambiente.

A avaliação de percepção de ruído foi produzida seguindo recomendações da medicina ocupacional e higiene e segurança do trabalho (RUNDMO, 1996; NELSON et al.., 1999; RABINOWITZ, 2000). Foram questionados se os voluntários reconheciam as fontes de ruído, o grau de incômodo gerado e a durabilidade do mesmo, bem como as perguntas abertas: queixas e ideias para resolução do problema de ruído no ambiente de trabalho.

E por fim a avaliação de uso do espaço e mobiliário feita em conjunto com a NBR 9050 - Acessibilidade a edificações, mobiliário, espaços e equipamentos urbanos (ABNT, 2005), onde foram questionados: tamanho e aparência do espaço, disposição do mobiliário. Finalizando com as perguntas abertas anteriormente colocadas.

O questionário completo foi aplicado juntamente com as avaliações psicológicas no Auditório da Radiologia do HC da UNICAMP.

\subsection{Avaliação das variáveis emocionais}

Foram usados instrumentais validados pelas áreas de psicologia e psiquiatria brasileiras de acordo com a variável estudada. Foram eles: avaliação de transtorno psiquiátrico, Questionário de Saúde Geral de Goldberg; avaliação dos sintomas depressivos, Escala de Depressão de Beck; avaliação dos sintomas de ansiedade, Inventário de Ansiedade Traço-Estado; avaliação das condições de sono, Pittsburgh Sleep Quality Index e Avaliação de sonolência diurna de Epworth; e avaliação do grau de estresse, Inventário de Sintomas de Estresse para Adultos de LIPP. A aplicação desses instrumentais foi realizada por profissionais especializados das áreas de psicologia e neurociências do sono com acompanhamento da pesquisadora responsável.

O procedimento inicial constou da preparação de 01 kit com os testes psicológicos e de sono que foi entregue para sujeitos após explicação e objetivos e 
foram respondidas de forma individual e auto administrada. A aplicação dos instrumentais foi feita em 02 dias, com duração aproximada de 03 hr totais. Todo o processo foi acompanhado pela pesquisadora responsável. O voluntário respondeu, de forma individual e auto administrada.

\subsection{Estatística}

A obtenção dos dados formou um banco com auxílio do software Excel 2010 (MICROSOFT, 2010) que foi analisada estatisticamente no software Statistical Package for Social Science - SPSS Statistics v. 22.0 (IBM, 2013) e no software GraphPad Prism v.6.0 (GRAPHPAD SOFTWARE INC., 2014). A descrição estatística da amostra se deu através de estudo das variáveis ambientais, psicológicas e fisiológicas mediante cálculo de valores de porcentagem, estatística descritiva com desvio padrão, valores mínimos, máximos, média e mediana. A estatística descritiva consistiu de apresentação da média, mediana, desvio-padrão. O nível de significância para os testes estatísticos foi de $5 \%$ ( $p \leq 0,05)$. Para comparação numérica foram usados os testes: i. U de Mann-Whitney; ii. coeficiente de correlação de Pearson; e iii. Bonferroni - ANOVA; iv. Fisher (LSD); v. correlação não paramétrica de Spearman. Para teste de distribuição gaussiana foram usados: $i$. teste de normalidade de Shapiro e ii. teste Kolmogorov-Smirnov com $\mathrm{P}$ value de DallalWilkinson-Lilliefor. Na avaliação de concentração hormonal, usaram-se análises de variância (ANOVA).

\section{Resultados}

\subsection{Perfil dos sujeitos}

O grupo de voluntários composto por médicos residentes do Setor da Imaginologia do $\mathrm{HC} / \mathrm{Campinas}$ foi selecionado devido a fatores como: níveis de estresse atenuados, estafa mental, cansaço físico, responsabilidade para com a vida, necessidade de estudo contínuo, plantão, responsabilidades de estudante, vida social prejudicada pela rotina do hospital, dentre outros. Neste item, os voluntários foram analisados juntos e de forma generalista, totalizando uma amostra de 16 médicos residentes.

A amostra conteve voluntários na faixa etária entre 24 a 35 anos. O estado civil foi composto de $94 \%$ de solteiros e $6 \%$ casados $(n=16)$. Com relação a ter filhos, $06 \%(\mathrm{n}=16)$ alegaram que os possuíam. Ao questioná-los sobre o turno de atividades da residência médica no hospital, 100\% ( $\mathrm{n}=16)$ afirmaram que frequentavam o hospital nos períodos da manhã e da tarde, a noite somente $62,5 \%(n=16)$. Com relação aos dias para realização das atividades $100 \%(n=16)$ respondeu que iam de segunda a sexta ao hospital, enquanto $(n=16) 18,75 \%$ disseram que também o frequentava aos sábados e domingos. Quanto ao sistema de plantão, 6,25\% $(\mathrm{n}=16)$ deles afirmaram não realizar plantões, pois se dedicavam a outras atividades dentro da própria residência médica. A maioria dos R1 e R2, principalmente este, fazia sistema de plantões. E assim como permitido pelo Manual do Residente (BRASIL, 2002), a escala de plantão de 12 h era a mais realizada ( $83 \%(\mathrm{n}=16)$ dos voluntários), seguida de 6 h ( $12 \%$ e $n=16)$ e 24 h ( $05 \%$ e $n=16)$. Contudo, a quantidade por semana de plantões realizados não estava de acordo com o manual, onde grande parte realizava de 02 a 04 plantões semanais.

A relação com os professores médicos apresentou-se prolixa e hostil em alguns momentos. A maioria dos médicos residentes relatou sentir receio de seus supervisores e que grande parte destes não provia espaço para uma relação amigável, sendo "sempre diretos e de pouca conversa", fazendo-os se sentirem inferiores e tímidos com relação a muitas dúvidas que poderiam ser tiradas. Contudo, isto contradisse o nível de relacionamento com os chefes marcado no questionário, onde $94 \%$ afirmou ser boa essa relação e $6 \%$ ruim $(n=16)$. Já a relação entre os próprios médicos residentes se mostrou melhor, com 53\% apontando para o "muito bom" e $41 \%$ para o "bom"; entretanto, aqui apareceram $6 \%$ para o "muito ruim". Esta porcentagem foi justificada pela falta de comprometimento que alguns R1 e R2 demonstraram.

Houveram queixas de sonolência diurna, acarretando em abuso de cafeína (53\%, n=16) durante as rotinas hospitalares. A realização de atividade física também esteve atrelada à queixa do sono. Nos horários livres, nos quais poderiam se exercitar, houve a troca desta atividade pelo sono mais prolongado ou outras tarefas, assim, 65\% $(\mathrm{n}=16)$ não se exercitavam apesar de saberem sua importância. Percebeu-se preocupação para com a própria saúde, pois o fumo não se tornou válvula de 
escape para 94\% (n=16) dos voluntários. Compensando, segundo relatos dos próprios médicos residentes, a falta de atividade física.

\subsection{Qualidade do ambiente construído}

\subsubsection{Iluminação}

A aferição do sistema luminotécnico averiguou a presença de baixa iluminância na maior parte do setor, especialmente nas salas de laudo e dormitório: sala de laudo [7] $M=17,63, M d=11,8, \quad S \_D=3,93$ ( $\mathrm{n}=290)$; sala de laudo [9] $\mathrm{M}=14,65, \mathrm{Md}=11,8$, S_D=4,43 ( $\mathrm{n}=290)$; dormitório $\mathrm{M}=71,93, \mathrm{Md}=35,5$, S_D=47,84 (n=290). Quando analisadas frente à normativa NBR/ISO 8995:1 (ABNT, 2013), tais valores encontram-se fora dos limites recomendados, mas dentro do esperado pelos usuários, uma vez que a norma não caracteriza corretamente ambientes como salas de laudo para Imaginologia. Além deste, obtiveram-se problemas como: posicionamento das luminárias, sua localização próxima às paredes e o tipo de acabamento usado tornaram a distribuição da luz não uniforme, o que fez com que as paredes virassem potenciais superfícies de ofuscamento; iluminância, a maior parte das áreas possuíam níveis abaixo dos recomendados por norma, enquanto alguns os possuíam em excesso, tornando o ambiente fora do contexto normativo; intensidade das lâmpadas, devido à potência de algumas delas, trechos de piso e parede transformaram-se em superfícies reflexivas, causando ou tornando-se possíveis pontos de ofuscamento. Apesar destes pontos negativos, um ponto positivo destacou-se: o padrão de tons usado nas paredes não era cansativo visualmente e remetia às cores comumente utilizadas em ambientes hospitalares, além de, se usado em conjunto com o sistema de iluminação artificial, poderia favorecer uma melhor distribuição da luz. Os ambientes gerais que compunham a Imaginologia não demonstraram integração entre os conceitos de conforto ambiental, bem-estar e estética espacial. Seus espaços careciam de humanização ambiental, desfavorecendo à boa percepção e cognição por parte dos usuários.

\subsubsection{Ambiente térmico}

A aferição do sistema térmico (temperatura e umidade relativa, especialmente) demonstrou valores dentro da NR 17 (ABNT, 2007). Temperatura: sala de laudo [7] $\mathrm{M}=24,99, \mathrm{Md}=25,04$,
S_D=0,34 ( $\mathrm{n}=290)$; sala de laudo [9] $\mathrm{M}=18,57$, $\mathrm{Md}=18,48, \mathrm{~S} \_\mathrm{D}=0,42(\mathrm{n}=290)$; dormitório $\mathrm{M}=22,10$, $\mathrm{Md}=22,10, \mathrm{~S} \_\mathrm{D}=0,44(\mathrm{n}=290)$. E umidade relativa: sala de laudo [7] $\mathrm{M}=59, \mathrm{Md}=59, \mathrm{~S} \_\mathrm{D}=1,55$ ( $\left.\mathrm{n}=290\right)$; sala de laudo [9] $\mathrm{M}=71, \mathrm{Md}=71, \mathrm{~S} \_\mathrm{D}=1,03$ ( $\mathrm{n}=290$ ); dormitório $\mathrm{M}=65, \mathrm{Md}=65, \mathrm{~S} \_\mathrm{D}=1,74$ ( $\left.\mathrm{n}=290\right)$. Dados estes que não incomodaram os médicos residentes, mas sim problemas relacionados à qualidade dos mesmos. Não havia controle da temperatura por parte dos médicos residentes, ficando isto a cargo do Setor da Manutenção do HC/Campinas. As temperaturas não eram constantes ao longo do dia, evitando o tédio térmico, mas atrapalhando a concentração e o desempenho dos usuários por distrações pelas sensações causadas. Não havia ajuste da temperatura de acordo com as roupas usadas pelos médicos residentes, como jalecos, roupas e sapatos fechados, o que aumentava o isolamento térmico das vestimentas. Também, não houve resfriamento sobre as fontes de calor. Essa inconstância na temperatura podia causar elevação e diminuição do ritmo cardíaco visando ajustar a temperatura do corpo à ambiental, pois o calor gerado pelo organismo devia ser dissipado em igual proporção ao ambiente, evitando sensações desconfortáveis. Desta forma, os ambientes com maiores índices de reprovação e insatisfação, segundo cálculos de PMV e PPD, foram as salas de laudo da US e a [7]. Os ambientes que fugiram da norma, segundo medições realizadas in loco, foram as salas de laudo US e a [7], consideradas quentes, e a sala de laudo [9], considerada fria para os padrões propostos. Com relação à umidade relativa, somente nos ambientes mais frios (sala de laudo [9] e sala de laudo RM 1,5T) obtiveram-se UR com valores próximos ou pouco acima do preconizado. Apesar da percentagem de pessoas insatisfeitas estar dentro dos limites na maioria das situações simuladas, foi perceptível a falta de preocupação com a integração dos elementos do sistema térmico para as pessoas que ali frequentavam, especialmente os médicos residentes que usam vestimentas específicas.

\subsection{Percepção Ambiental}

Com a análise do espaço construído avançou-se no sentido de entender como os médicos residentes percebiam seu ambiente de trabalho de acordo com o grupo os quais estavam inseridos. Aos médicos residentes questionou-se se o sistema de iluminação favorecia a existência de sombras, responderam que 
sim: R1 66,7 \% (n=4), R2 40\% (n=5) e R3 40\% (n=5) por causa do não ajustamento da luz de acordo com o layout dos ambientes. Com relação ao desconforto causado pelo ofuscamento, sentiam desconforto: R1 16,7\% (n=6), R2 0\% (n=5) e R3 0\% (n=5). Esses dois problemas levaram a: condições de iluminação disponíveis não favoreciam uniformidade da luz com R1 83,3\% (n=6), R2 80\% ( $n=5)$ e R3 80\% (n=5); e iluminação não diferenciada nas zonas de atividades dentro de um mesmo ambiente com R1 50\% ( $n=6)$, R2 40\% ( $n=5)$ e R3 40\% ( $=5)$. Apesar dos dados refletirem que o sistema de iluminação tinha problemas, os questionamentos feitos sobre as preferências destas mostrou um lado específico de quem trabalha sob as condições dos médicos residentes: $100 \%$ dos 03 grupos afirmaram não preferir uso de luz natural dentro das salas de laudo devido à natureza das atividades realizadas, mesmo $83,3 \%$ dos R1 ( $n=6)$ e $60 \%$ dos R2 ( $n=5)$ preferindo a luz natural, eles gostariam que ela fosse aproveitada dentro do espaço do setor. Todos os voluntários do grupo dos R3 não tinham preferência pela luz natural. Quanto à luz local ser estimulante a maioria dos médicos residentes foram enfáticos ao afirmar que não: R1 83,3\% (n=6), R2 100\% (n=5) e R3 100\% $(n=5)$. Assim, 66,7\% ( $n=6)$ dos R1, 60\% ( $n=5)$ dos R2 e $20 \%(n=5)$ dos R3 se encontravam satisfeitos com a condição real, por exemplo: a baixa iluminação das salas de laudos para a execução da atividade de laudear era necessária, pois melhorava a qualidade das imagens, facilitando o diagnóstico.

A segunda parte questionou o sistema térmico. No momento da avaliação e com as vestimentas usadas (que variaram entre 0,81 a 1,16 clo) foram identificadas as seguintes sensações térmicas. R1 $(\mathrm{n}=6): 100 \%$ relataram estarem neutros. $\mathrm{R} 2(\mathrm{n}=5)$ : $20 \%$ muito frio, $20 \%$ com frio, $20 \%$ neutro e $40 \%$ com calor. R3 ( $n=5): 20 \%$ com frio, $60 \%$ neutro e $20 \%$ com calor. Quando perguntados como estava o ambiente térmico junto a eles naquele momento, $50 \%$ dos $\mathrm{R} 1$ ( $\mathrm{n}=6$ ) afirmaram estar neutro, enquanto os $50 \%$ restante disseram estar confortável. Os R2 $(\mathrm{n}=5)$ tiveram $40 \%$ em desconfortável e $60 \%$ em neutro. E os R3 20\% desconfortável, 60\% neutro e $20 \%$ confortável. Resultados estes que se mostraram compatíveis em como os médicos residentes prefeririam o ambiente térmico naquele momento: dos R1 ( $n=6), 50 \%$ gostariam que o ambiente continuasse neutro, $33,3 \%$ quente e $16,7 \%$ bem mais quente; $\mathrm{R} 2$ ( $\mathrm{n}=5$ ), 40\% ambiente permanecesse igual (neutro), $20 \%$ quente e $40 \%$ mais quente; já os R3 $60 \%$ preferiam o ambiente neutro, enquanto $40 \%$ gostariam do ambiente frio (figuras 1 e 2).

Figura 1: Sensação térmica dos médicos residentes do Setor da Imaginologia do HC/Campinas no momento da avaliação.

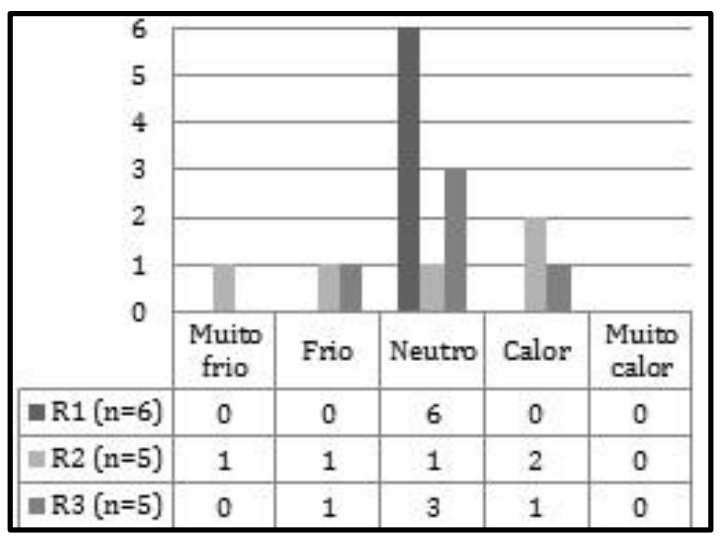

Figura 2: Preferência térmica dos médicos residentes do Setor da Imaginologia do HC/Campinas.

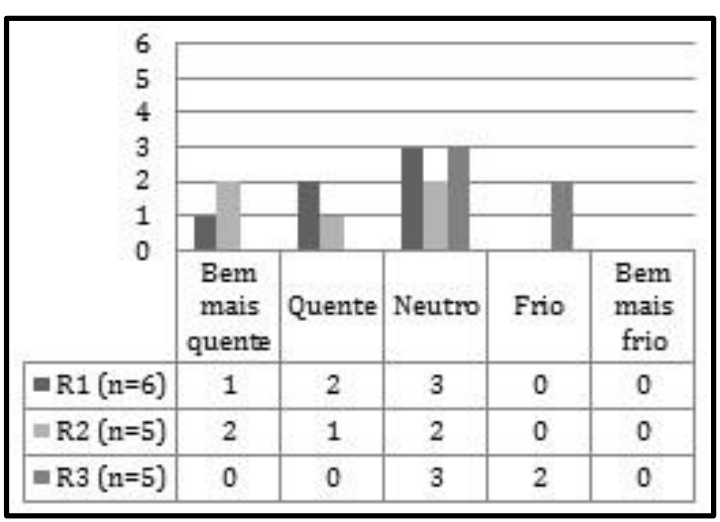

A terceira parte referiu-se ao ruído. A presença do ruído esteve presente para a maioria dos médicos residentes: $100 \%$ para os $\mathrm{R} 2(\mathrm{n}=5)$ e $60 \%$ para os $\mathrm{R} 3$ $(\mathrm{n}=5)$, apenas $33,3 \%$ dos R1 afirmaram presenciar ruídos no ambiente do setor. Sua constância também foi detectada por: $50 \%$ dos R1 ( $n=6), 100 \%$ dos R2 $(\mathrm{n}=5)$ e $40 \%$ dos R3. Alcançando o dormitório, item detectado por $33,3 \%$ dos $\mathrm{R} 1$ ( $\mathrm{n}=6$ ), $80 \%$ dos $\mathrm{R} 2$ ( $\mathrm{n}=5$ ) e $20 \%$ dos $R 3(n=5)$. Os ruídos detectados por cada grupo foram: i. conversas externas, 83,3\% R1 ( $n=6)$, $100 \%$ R2 ( $n=5)$ e $40 \%$ R3 ( $n=5)$; conversas internas, $83,3 \%$ R1 (n=6), 60\% R2 (n=5) e 20\% R3 (n=5); máquinas, $83,3 \%$ R1 ( $n=6), 20 \%$ R2 ( $n=5)$ e $60 \%$ R3 $(\mathrm{n}=5)$; ruídos externos, 66,7\% R1 ( $\mathrm{n}=6), 80 \%$ R2 $(\mathrm{n}=5)$ e $0 \%$ R3 ( $\mathrm{n}=5)$; ruídos internos, 66,7\% R1 $(n=6), 40 \%$ R2 $(n=5)$ e $0 \%$ R3 $(n=5)$. Houve reclamações quanto à falta de silêncio de pacientes e 
funcionários do setor ao passarem frente às salas de laudo.

Para saber como os médicos residentes se sentiam frente às condições ambientais consideradas por eles inadequadas questionou-se quais efeitos negativos os mesmos sentiam de acordo com a variável. Iluminação, para os R1 os efeitos mais presentes foram a dor de cabeça $(33,3 \%, n=6)$ e a irritação $(33,3 \%, \mathrm{n}=6)$, seguidos da fadiga, cansaço e diminuição da produtividade, todos com 16,7\% $(\mathrm{n}=6)$; para os R2 foram o cansaço, $(60 \%, \mathrm{n}-5)$, fadiga $(40 \%, n=5)$ e irritação $(20 \%, n=5)$ - não foram identificadas pontuações nos quesitos dor de cabeça e diminuição de produtividade; e para os R3, cansaço $40 \%(n=5)$ e fadiga $20 \%(n=5)$. Temperatura, os R1 marcaram como consequências dor de cabeça, fadiga, cansaço e diminuição de produtividade, todos com 16,7\% ( $\mathrm{n}=6)$; os R2 consideraram o cansaço $(80 \%, n=5)$ e a fadiga $(40 \%, n=5)$ como os principais efeitos sentidos; e os R3 a fadiga (40\%, $\mathrm{n}=5)$ e irritação $(20 \%, \mathrm{n}=5)$. Ruído, os $\mathrm{R} 1$ foram os que mais sentiram os efeitos desta variável, $50 \%$ $(\mathrm{n}=6)$ declaram ter irritação, 33,3\% $(\mathrm{n}=6)$ cansaço, $16,7 \% \quad(n=6)$ dor de cabeça e zumbido; os R2 revelaram efeitos específicos como o cansaço e irritação, ambos c $60 \%(n=5)$, e dor de cabeça $(20 \%$, $\mathrm{n}=5)$; já os R3 afirmaram sentir somente irritação (60\%, n=5). Dos 03 grupos analisados, os médicos residentes do primeiro foram os que mais sentiram os efeitos negativos quando o ambiente se encontra inadequado à realização das atividades, seguidos dos R2 e R3. Isto demonstrou a evolução gradual da adaptação ambiental e sensorial desde as primeiras impressões no início da residência médica as após 03 anos frequentando o mesmo espaço.

A seção final referiu-se ao espaço e mobiliário dos ambientes primários. A adequação do tamanho espacial à realização das atividades foi dita como sim pela maioria dos voluntários: R1 50\% (n=6), R2 $100 \%(n=5)$ e R3 40\% (n=5). A disposição do mobiliário também foi questionada e neste ponto as opiniões dividiram: apenas $16,7 \%$ dos $\mathrm{R} 1 \quad(\mathrm{n}=6)$ consideraram a disposição adequada, enquanto $80 \%$ de ambos $\mathrm{R} 2$ ( $\mathrm{n}=5)$ e $\mathrm{R} 3$ ( $\mathrm{n}=5)$ responderam que sim. Conflitando com a análise ergonômica de uso apresentada anteriormente, a qual demonstrou vários pontos de conflitos tanto de acessibilidade quanto de segurança. Com relação à agradabilidade do espaço interno do setor, $100 \%$ dos $\mathrm{R} 1$ ( $\mathrm{n}=6), 80 \%$ dos R2 (n=5) e dos R3 ( $n=5)$ responderam que não gostavam da aparência, considerando-o feio e antigo.

Ao final da avaliação de percepção ambiental voluntários de cada grupo expuseram suas queixas e soluções referentes aos 04 temas abordados. É perceptível o grau de cobrança espacial entre os 03 grupos: os R1 listaram 11 soluções frente ao que os mesmos consideravam inadequados existir em um ambiente de trabalho, tendo sido os mais críticos dos 03 grupos, os R2 listaram 09, enquanto os R3 06. Contudo, constatou-se que os R3 apresentaram soluções concisas e próprias daqueles que têm maior vivência no ambiente, conhecedor das deficiências e burocracia locais. Das 06 soluções dadas por aqueles, 05 repetiram-se entre os R1 e R2. Foram elas: inserção de luz de tarefa nas estações de trabalho; ajuste manual e progressivo do ar condicionado; sinalização de silêncio/isolamento acústico das salas de laudo devido às constantes conversas externas próximas às salas de laudo; modernização de equipamentos e mobiliário; e melhorias espaciais com adequação e reforma dos ambientes, modernizando-os e inserindo elementos necessários à realização das atividades.

Os R1 foram os mais críticos, seguidos dos R2 e R3. Constatando-se que o desconforto ambiental sentido decresce à medida que o ambiente é vivenciado e suas falhas reconhecidas com o amadurecimento pessoal e profissional no local de residência médica. A análise da correlação das condições ambientais e as notas atribuídas no questionário de percepção ambiental indicou correlação positiva entre os escores de percepção ambiental por grupo: percepção ambiental R1 vs. R2 (r de Spearman = $+0,0140$ ), percepção ambiental R1 vs. R3 ( $\mathrm{r}$ de Spearman $=+0,0002)$ e percepção ambiental R2 vs. R3 (r de Spearman $=+0,0006)$. Foram correlacionadas essas percepções ambientais com as condições ambientais e nenhuma relação foi encontrada. Contudo, encontrou-se associação negativa entre percepção ambiental dos grupos R1 e R2 com a iluminância do setor: percepção ambiental $\mathrm{R} 1$ vs. iluminância ( $\mathrm{r}$ de Spearman $=-0,0476$ ) e percepção ambiental R2 vs. iluminância ( $\mathrm{r}$ de Spearman $=-0,0056)$. Constatando a preferência pela quantidade de baixa iluminância in loco devido 
a sua necessidade para a realização das atividades no setor.

A análise ambiental contribuiu para a visualização das condições em que o Setor da Imaginologia do HC/Campinas se encontrava. Os ambientes não demonstraram integração entre os conceitos de conforto ambiental, bem-estar e estética espacial. Seus espaços careciam de cuidados ambientais, falha esta percebida pela diferenciação do grau de cobrança e percepção espacial entre os médicos residentes, desfavorecendo a percepção e cognição dos usuários.

\subsection{Transtornos psicológicos}

\subsubsection{Transtorno psiquiátrico}

O uso do QSG visou identificar a existência e o nível do distúrbio psiquiátrico e identificar nesta população, potenciais casos de estudo.

Em um primeiro momento o QSG foi analisado particionado em seus 05 fatores: F1, estresse psíquico; F2, desejo de morte; F3, falta de confiança na própria capacidade de desempenho; F4, distúrbios do sono; e F5, distúrbios psicológicos. As pontuações obtidas foram mostradas em ordem decrescente dos valores obtidos para cada fator e comparadas com o valor padrão base: 1,89. O F1 Estresse: i. R2, 03 de 04 valores acima do padrão; ii. R1, 02 de 05 valores acima do padrão; iii. R 3, 02 de 05 valores acima do padrão. F2 - Desejo de morte: i. R2, apesar dos valores obtidos, este grupo não apresentou valores acima do limite padrão; ii. R3, obteve um único valor acima do padrão; iii. R1, assim como os R2 não tiveram valores acima do padrão. F3 - Baixa autoestima: i. R2, todos os voluntários deste grupo obtiveram valores acima do padrão; ii. R1, 04 dos 05 valores acima do padrão; iii. R3, 02 dos 05 valores acima do padrão. F4 Distúrbios do sono: i. R2, 03 dos 04 valores acima do padrão; ii. R3, apesar de ter ficado em segundo lugar neste item, este grupo obteve 02 de 05 valores acima da média; iii. R1, 03 dos 05 valores acima do padrão. E para o F5 - Distúrbios psicológicos: i. R2, 02 de 04 valores acima da média; ii. R1, 03 de 05 valores acima do padrão; iii. R3, 01 de 05 valores acima do padrão. Com os dados obtidos, conclui-se que o grupo dos R2 teve destaque em 100\% dos fatores, mesmo quando seus valores não alcançaram o valor padrão, seguido dos R1 e R3 (tabela 1).
Tabela 1: QSG particionado por fator dos médicos residentes do Setor da Imaginologia do HC/Campinas

\begin{tabular}{|c|c|c|c|c|c|}
\hline \multicolumn{6}{|c|}{ a. F1: Estresse psíquico } \\
\hline Grupo & Intervalo & M & S_D & Md & $\alpha^{*}$ \\
\hline $\mathrm{R} 1$ & $2,1 H 1,1$ & 1,48 & 0,41 & 1,3 & 0,3612 \\
\hline $\mathrm{R} 2$ & $2,3 Н 1,69$ & 1,99 & 0,22 & 1,99 & 0,2176 \\
\hline R3 & $2,1 Н 1,23$ & 1,47 & 0,33 & 1,23 & 0,2945 \\
\hline \multicolumn{6}{|c|}{ b. F2: Desejo de morte } \\
\hline Grupo & Intervalo & $\mathrm{M}$ & S_D & $\mathrm{Md}$ & $\alpha^{*}$ \\
\hline $\mathrm{R} 1$ & 1,5 H 1 & 1,15 & 0,18 & 1,12 & 0,1613 \\
\hline $\mathrm{R} 2$ & $1,8 Н 1,4$ & 1,55 & 0,19 & 1,56 & 0,1912 \\
\hline R3 & $2,37 \mathrm{H} 1$ & 1,27 & 0,55 & 1 & 0,4803 \\
\hline \multicolumn{6}{|c|}{ c. F3: Baixa autoestima } \\
\hline Grupo & Intervalo & M & S_D & Md & $\alpha^{*}$ \\
\hline $\mathrm{R} 1$ & $2,3 \mapsto 1,7$ & 2,06 & 0,25 & 2,23 & 0,2223 \\
\hline $\mathrm{R} 2$ & 3,3 H 2,1 & 2,48 & 0,47 & 2,26 & 0,4608 \\
\hline R3 & $2,8 Н 1,5$ & 1,89 & 0,45 & 1,7 & 0,3940 \\
\hline \multicolumn{6}{|c|}{ d. F4: Distúrbios de sono } \\
\hline Grupo & Intervalo & M & S_D & $\mathrm{Md}$ & $\alpha^{*}$ \\
\hline $\mathrm{R} 1$ & $2 H 1,3$ & 1,70 & 0,24 & 1,83 & 0,2149 \\
\hline R2 & $2,7 H 1,8$ & 2,08 & 0,34 & 1,91 & 0,3351 \\
\hline R3 & 3 Н 1,2 & 1,73 & 0,67 & 1,33 & 0,5888 \\
\hline \multicolumn{6}{|c|}{ e. F5: Distúrbios psicológicos } \\
\hline Grupo & Intervalo & M & S_D & $\mathrm{Md}$ & $\alpha^{*}$ \\
\hline $\mathrm{R} 1$ & $2,9 \mapsto 1,4$ & 2 & 0,52 & 2 & 0,4538 \\
\hline $\mathrm{R} 2$ & 2,2 H 1,7 & 1,95 & 0,21 & 1,95 & 0,2020 \\
\hline R3 & $2,4 \dot{H} 1,3$ & 1,64 & 0,39 & 1,5 & 0,3444 \\
\hline
\end{tabular}

${ }^{*} \mathrm{p}<0,05$

\subsubsection{Depressão}

O instrumental BDI coletou descrições textuais dos sujeitos sobre seus sintomas avaliando a intensidade e severidade deles, tomando como base a tríade de cognições negativas relacionadas ao mundo, ao futuro e a si mesmo.

Os resultados obtidos mostraram que os R2 obtiveram as maiores pontuações, mas abaixo do limite: 10 e 15 , respectivamente $(50 \%$ do $\mathrm{n}=4)$, seguidos pelos R3 e R1 (tabela 2).

Tabela 2: BDI dos médicos residentes do Setor da Imaginologia do HC/Campinas.

\begin{tabular}{|c|c|c|c|c|c|}
\hline Grupo & Intervalo & M & S_D & $\mathrm{Md}$ & $\alpha^{*}$ \\
\hline R1 & 0 H 6 & 3,2 & 1,9390 & 3 & 1,6996 \\
\hline $\mathrm{R} 2$ & $1 H 15$ & 8 & 5,1478 & 8 & 5,0447 \\
\hline R3 & $2 \mapsto 8$ & 4 & 2,1909 & 4 & 1,9203 \\
\hline
\end{tabular}

\subsubsection{Ansiedade}

Para a avaliação dos sintomas de ansiedade foi usado o instrumental STAI. Os R2 foram os que apresentaram maiores escores na ansiedade estado e traço. Metade da população deste grupo obteve valores acima da pontuação limite de 40 pontos em 
ambos (entre 53 e 60 pontos), enquanto a outra metade obteve valores muito próximos a esta (entre 38 e 39 pontos). Os R1 tiveram $40 \%(n=5)$ de sua população com valores acima da pontuação limite (entre 41 e 50 pontos) e $20 \%$ com valores muito próximos (36 e 38 pontos). Já os R3 tiveram apenas $20 \%$ de sua população com valores acima do limite (52 e 55) e $20 \%$ em só no ansiedade Estado (42), o que fez com que a média e mediana para este ficasse acima dos valores obtidos para os R1 (tabela 3).

Tabela 3: IDATE dos médicos residentes do Setor da Imaginologia do HC/Campinas.

\begin{tabular}{|c|c|c|c|c|c|}
\hline \multicolumn{6}{|c|}{ a. Traço } \\
\hline Grupo & Intervalo & M & S_D & $\mathrm{Md}$ & $\alpha^{*}$ \\
\hline R1 & $29 H 50$ & 37,4 & 7,914 & 38 & 6,9373 \\
\hline R2 & 39 H 60 & 47,7 & 9,093 & 46 & 8,9112 \\
\hline R3 & $27 \mathrm{H}^{2}$ & 39,6 & 9,2 & 39 & 8,0640 \\
\hline \multicolumn{6}{|c|}{ b. Estado } \\
\hline Grupo & Intervalo & M & S_D & $\mathrm{Md}$ & $\alpha^{*}$ \\
\hline R1 & $25 \mathrm{H} 44$ & 36,6 & 6,829 & 36 & 5,9861 \\
\hline R2 & $38 \mathrm{H}$ & 48,7 & 10,75 & 48,5 & 10,540 \\
\hline R3 & $29-52$ & 36,8 & 8,009 & 33 & 7,0209 \\
\hline
\end{tabular}

\subsubsection{Estresse}

$\mathrm{O}$ uso do ISS visou identificar os sintomas e intensidade de estresse. Os valores totais obtidos demonstraram que os $\mathrm{R} 2$ se encontraram mais propensos ao estresse do que os R3 e R1, em ordem decrescente, segundo dados demonstrados na tabela 4.

Tabela 4: ISS total dos médicos residentes: a. FT; b. PT e c. TT.

\begin{tabular}{|c|c|c|c|c|c|}
\hline \multicolumn{6}{|l|}{ a. FT } \\
\hline Grupo & Intervalo & M & S_D & $\mathrm{Md}$ & $\alpha^{*}$ \\
\hline R1 & 0 H 7 & 3,2 & 2,5612 & 3 & 2,2450 \\
\hline $\mathrm{R} 2$ & 6 H 12 & 8,75 & 2,3848 & 8,5 & 2,3371 \\
\hline R3 & 0 Н 6 & 3,6 & 2,0591 & 4 & 1,8049 \\
\hline \multicolumn{6}{|l|}{ b. PT } \\
\hline Grupo & Intervalo & M & S_D & $\mathrm{Md}$ & $\alpha^{*}$ \\
\hline R1 & 0 H 5 & 2 & $1, \overline{6733}$ & 2 & 1,4667 \\
\hline $\mathrm{R} 2$ & $1 H 15$ & 7,75 & 5,8896 & 7,5 & 5,7717 \\
\hline R3 & $0 \mapsto$ & 1,4 & 2,3323 & 0 & 2,0444 \\
\hline \multicolumn{6}{|l|}{ c. TT } \\
\hline Grupo & Intervalo & M & S_D & $\mathrm{Md}$ & $\alpha^{*}$ \\
\hline R1 & $1 \mapsto 10$ & 5,2 & 3,6 & 3 & 3,1555 \\
\hline $\mathrm{R} 2$ & $7 \mathrm{H}$ & 16,5 & 8,2613 & 16 & 8,096 \\
\hline R3 & $0 Н 12$ & 5 & 3,8987 & 4 & 3,4173 \\
\hline
\end{tabular}

A classificação por fase (alarme, resistência e exaustão) ilustrou como se deu a distribuição por níveis de residência médica. Onde os R2 apareceram com maiores frequência e intensidade quando se tratava dos limites para cada fase. Em segundo lugar estavam os R3 e por último os R1. A fase de alarme identificada não apresentou complicações por ser o estresse motivador à ação, que tira o indivíduo da inércia e ajuda na produção da adrenalina. $\mathrm{Na}$ resistência, o organismo se encontrou mobilizado e tentou buscar o equilíbrio através da produção do cortisol, por exemplo. Houve também a somatização de problemas físicos e psicológicos. E na última, a exaustão, o corpo estava totalmente exaurido e doenças graves se fizeram presentes. Dos 03 grupos, os R2 apresentaram maiores condições de risco na saúde.

\subsubsection{Qualidade do Sono}

A análise da qualidade do sono se deu através da ferramenta PSQI e visou averiguar diversos pontos de como e quando se dava o período de sono e se esse era $\mathrm{o}$ mais adequado para o descanso após as atividades no ambiente hospitalar.

Verificou-se que os R2 apresentaram tempo para iniciar o sono elevado, demorando em média cerca de 36,6 minutos, com média de sono por noite $6 \mathrm{~h}$ e $24 \mathrm{~min}$. Os R3 levaram menos tempo para dormir: média de $12 \mathrm{~min}$, mas tiveram média de sono menor de aproximadamente $6 \mathrm{~h}$. Já os R1 demoraram cerca de 12,8 min para iniciar o sono, o qual durou em média 7 h e 12 min (tabela 5). Estando os R2 e os R3 abaixo da média da população adulta em geral e os R1 um pouco acima desta média de sono por noite: 7 e $9 \mathrm{~h}$. Contudo, deve-se lembrar que a quantidade de horas de sono para descanso varia entre indivíduos.

Tabela 5: PSQI: a. tempo para iniciar o sono e b. tempo de sono por noite em médicos residentes do Setor da Imaginologia do HC/Campinas.

\begin{tabular}{|c|c|c|c|c|c|c|}
\hline \multicolumn{7}{|c|}{ a. Tempo para iniciar o sono dos médicos residentes } \\
\hline Grupo & Inte & valo & M & S_D & Md & $\alpha^{*}$ \\
\hline R1 & 4 & 30 & 12,8 & 9,45 & 10 & 8,28 \\
\hline R2 & 3 & 60 & 36,6 & 21,49 & 30 & 18,84 \\
\hline R3 & 5 & 30 & 12 & 9,79 & 5 & 8,58 \\
\hline \multicolumn{7}{|c|}{ b. Tempo de sono por noite dos médicos residentes } \\
\hline Grupo & Inte & valo & M & S_D & Md & $\alpha^{*}$ \\
\hline R1 & 420 & 480 & 432 & 24 & 420 & 21,03 \\
\hline R2 & 360 & 420 & 384 & 29,39 & 360 & 25,76 \\
\hline R3 & 300 & 480 & 360 & 65,72 & 360 & 57,61 \\
\hline
\end{tabular}

Com relação à qualidade subjetiva do sono, $80 \%$ dos R1 a possuíram entre muito boa e boa e $20 \%$ como muito ruim. Os R2 classificaram $20 \%$ como boa e $80 \%$ como ruim e muito ruim. E os R3, 25\% deles classificaram a qualidade do sono como boa e $75 \%$ 
como ruim. Quanto à eficiência do sono, $40 \%$ dos R2 a classificaram como boa e $60 \%$ como muito boa. Enquanto $100 \%$ dos R1 e R3 a consideraram como muito boa. O uso de medicamentos apareceu somente nos R2 com 20\%. Os R1 e R3 não indicaram uso de medicamentos. A porcentagem dos R2 é superior à taxa média da população brasileira de 6,9\% (tabela 6).

Tabela 6: PSQI: a. qualidade do sono; b. eficiência do sono; e c. uso de medicamentos para dormir dos médicos residentes do Setor da Imaginologia do HC/Campinas.

\begin{tabular}{lcccc}
\hline \multicolumn{4}{l}{ a. Qualidade do sono } & \multicolumn{2}{l}{} \\
Grupo & M & S_D & Md & $\alpha^{*}$ \\
R1 & 1,4 & 0,8 & 1 & 0,70 \\
R2 & 2 & 0,63 & 2 & 0,55 \\
R3 & 1,75 & 0,43 & 2 & 0,42 \\
b. Eficiência do sono & & & \\
Grupo & M & S_D & Md & $\alpha^{*}$ \\
R1 & 0 & 0 & 0 & 0 \\
R2 & 0,4 & 0,48 & 0 & 0,42 \\
R3 & 0 & 0 & 0 & 0 \\
c. Uso de medicamentos para dormir & \\
Grupo & M & S_D & Md & $\alpha^{*}$ \\
R1 & 0 & 0 & 0 & 0 \\
R2 & 0,4 & 0,8 & 0 & 0,70 \\
R3 & 0 & 0 & 0 & 0 \\
\hline$*$
\end{tabular}

Quando indagados sobre a indisposição ou falta de entusiasmo para realizar as atividades diárias na residência médica, os $\mathrm{R} 1$ responderam que: tinham um leve problema $(80 \%, \mathrm{n}=4))$ e um problema razoável $(20 \%, \mathrm{n}=1)$. Os $\mathrm{R} 2$ : problema leve $(20 \%$, $\mathrm{n}=1)$, problema razoável $(60 \%, \mathrm{n}=3)$ e grande problema $(20 \%, n=1)$. Já os $\mathrm{R} 3$ : afirmaram ter nenhuma dificuldade $(20 \%, \mathrm{n}=1)$, problema leve $(60 \%, n=3)$ e problema razoável $(20 \%, n=1)$.

Desta forma, o PSQI total foi de: R 1 com valores entre 4 e 10 pontos; R 2 entre 5 e 12; e os R 3 entre 4 e 8 pontos. Observou-se que dentre os 03 níveis de residência, os $\mathrm{R} 3$ foram os que possuíram a pior qualidade de sono, tendo o dobro do valor mínimo admitido para não possuir problemas relacionados ao sono (tabela 7).

Tabela 7: PSQI total dos médicos residentes do Setor da Imaginologia do HC/Campinas.

\begin{tabular}{|c|c|c|c|c|c|}
\hline Grupo & Intervalo & $\mathrm{M}$ & S_D & $\mathrm{Md}$ & $\alpha^{*}$ \\
\hline R1 & $4 H 10$ & 6 & 2,09 & 5 & 1,83 \\
\hline $\mathrm{R} 2$ & $5 \mapsto 12$ & 9,8 & 2,48 & 11 & 2,17 \\
\hline R3 & 4 H 8 & 5,5 & 1,65 & 5 & 1,62 \\
\hline
\end{tabular}

A ESE visou avaliar as chances dos médicos residentes terem sonolência diurna. Ao traçar o escore de todos os voluntários percebeu-se que os 03 grupos apresentaram valores acima de 10 (80\% do total), contribuindo para o diagnóstico de Sonolência Diurna Excessiva (SDE) e ultrapassando o valor médio da população de 11,6\% a 36\%. Quando separados por nível de residência médica obteve-se: R1, $80 \%$ deles apresentaram valores acima de 10 . Os R2 tiveram $100 \%$ de sua amostra com valores superiores a 11 . Já os $\mathrm{R} \quad 375 \%$ apresentaram valores entre 11 e 15 (tabela 8).

Tabela 8: ESE dos médicos residentes do Setor da Imaginologia do HC/Campinas.

\begin{tabular}{cccccc}
\hline Grupo & Intervalo & M & S_D & Md & $\alpha^{*}$ \\
R1 & $5 H_{1} 19$ & 12,8 & 4,66 & 14 & 4,08 \\
R2 & $11 H^{H}$ & 15,2 & 2,31 & 16 & 2,02 \\
R3 & $5 H^{H} 15$ & 11,25 & 3,89 & 12,5 & 3,81 \\
\hline${ }^{*} \mathrm{p}<0,05$ & & & & &
\end{tabular}

A análise estatística dos dados psicológicos contou com a aplicação do teste Mann-Whitney e o teste de Fisher. O primeiro constatou não haver diferença significativa entre mulheres e homens, bem como entre os sintomas psicológicos e idades dos sujeitos para todos os testes. Já o segundo comparou os pares de médias para os instrumentais referentes à ansiedade e estresse onde também detectou não haver diferenças significativas entre os dados.

\subsubsection{Correlações}

A análise das correlações entre as variáveis ambientais, psicológicas (ansiedade, depressão, estresse e sono) e fisiológicas (cortisol e melatonina) visou indicar a força e a direção (positiva ou negativa) da relação linear entre duas variáveis. Assim, foram correlacionadas variáveis dentro dos três âmbitos relacionados de acordo com o grupo de residência médica.

A análise da correlação das condições ambientais e as notas atribuídas no questionário de percepção ambiental indicou correlação positiva entre os escores de percepção ambiental por grupo: a. percepção ambiental R1 vs. R2 (r de Spearman = $+0,0140$ ), b. percepção ambiental R1 vs. R3 (r de Spearman $=+0,0002)$ e c. percepção ambiental R2 vs. R3 ( $\mathrm{r}$ de Spearman $=+0,0006$ ). Também foram correlacionadas essas percepções ambientais com as condições ambientais e nenhuma relação foi 
encontrada. Contudo, encontrou-se associação negativa entre a percepção ambiental dos grupos R1 e R2 com a iluminância do setor: a. percepção ambiental R1 vs. iluminância ( $\mathrm{r}$ de Spearman = 0,0476) e b. percepção ambiental R2 vs. iluminância ( $\mathrm{r}$ de Spearman $=-0,0056)$. Constatando a preferência pela quantidade de baixa iluminância in loco devido a sua necessidade para a realização das atividades no setor. Já a relação entre as 03 percepções ambientais e a temperatura do setor demonstrou comportamento de correlações em linhas verticais (VL).

Figura 3: Gráfico de correlação de Spearman entre os escores de percepção ambiental por grupo no Setor da Imaginologia do Hospital de Clínicas da UNICAMP/Campinas: a. percepção ambiental R1 vs. R2; b. percepção ambiental R1 vs. R3; c. percepção ambiental R2 vs. R3.

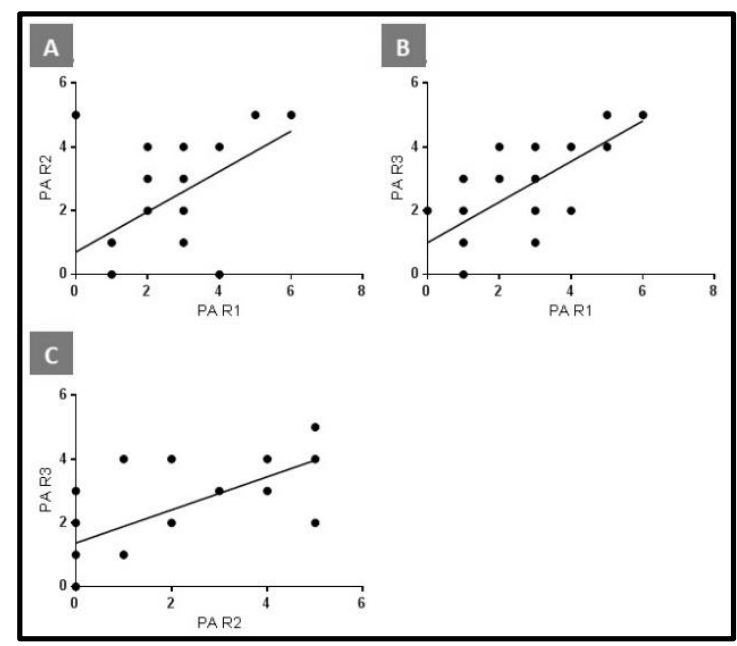

Figura 4: Gráfico de correlação de Spearman entre os escores de percepção ambiental por grupo no Setor da Imaginologia do Hospital de Clínicas da UNICAMP/Campinas: a. percepção ambiental R1 vs. iluminância; b. percepção ambiental R2 vs. iluminância.

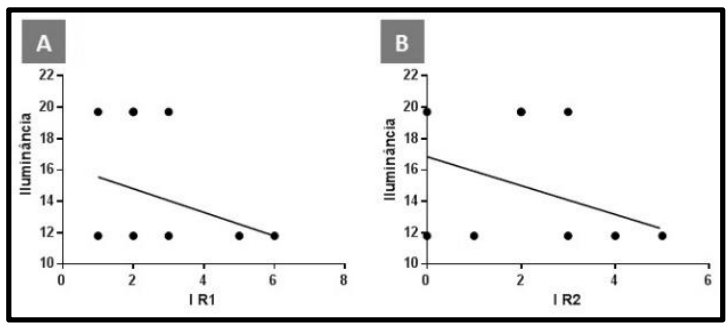

R1. A relação das variáveis psicológicas com a iluminação culminou em correlações positivas para a rotina de atividade: a. iluminância vs. depressão ( $\mathrm{r}$ de Spearman $=+0,0078)$; b. iluminância vs. estresse ( $\mathrm{r}$ de Spearman $=+0,0010)$; e c. iluminância vs. qualidade do sono ( $\mathrm{r}$ de $S$ pearman $=+0,0078$ ) (figura 5). A relação entre as variáveis psicológicas com a temperatura também apresentou correlações positivas: a. temperatura vs. A-estado ( $\mathrm{r}$ de Spearman $=+<0,0001) ;$ b. temperatura vs. T-estado ( $\mathrm{r}$ de $S$ pearman $=+0,0002)$; e c. temperatura vs. transtorno psiquiátrico ( $\mathrm{r}$ de Spearman $=+<0,0001$ ) (figura 6).

Figura 5: Gráfico de correlação de Spearman entre as variáveis psicológicas e a iluminância na rotina de atividade dos R1 no Setor da Imaginologia do Hospital de Clínicas da UNICAMP/Campinas: a. iluminância vs. depressão; b. iluminância vs. estresse; e c. iluminância vs. qualidade do sono.

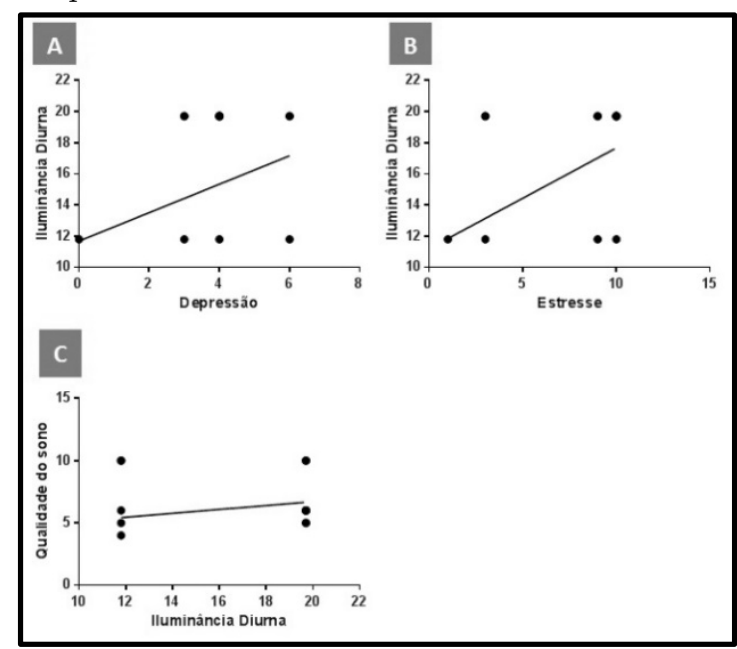

Figura 6: Gráfico de correlação de Spearman entre as variáveis psicológicas e a temperatura na rotina de atividade dos R1 no Setor da Imaginologia do Hospital de Clínicas da UNICAMP/Campinas: a. temperatura vs. A-estado; b. temperatura vs. T-estado; c. temperatura vs. transtorno psiquiátrico.

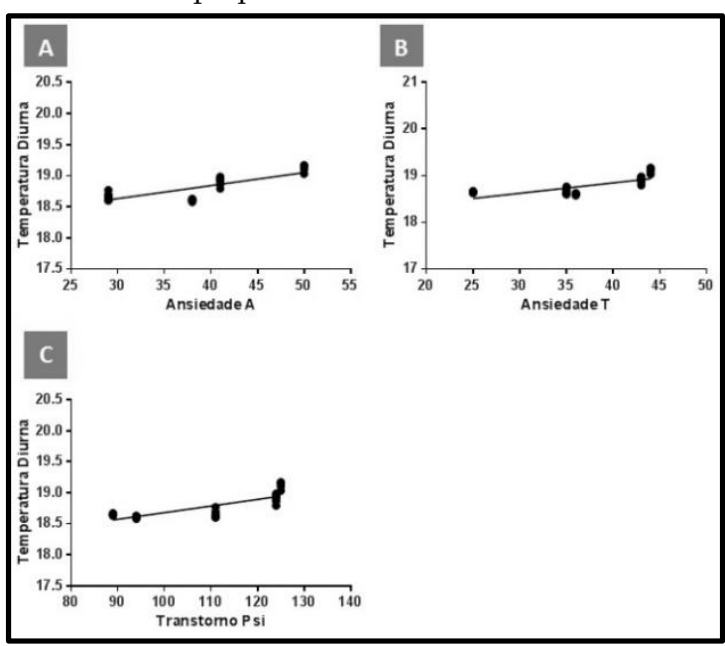

R2. Os médicos residentes do segundo ano apenas apresentaram relações entre a umidade relativa e as 
variáveis psicológicas para 2 das 4 rotinas identificadas: a. UR vs. estresse ( $\mathrm{r}$ de Spearman = 0,0037); b. UR vs. transtorno psiquiátrico ( $\mathrm{r}$ de Spearman $=-0,0037)$; e c. UR vs. qualidade do sono ( $\mathrm{r}$ de Spearman $=+<0,0001$ ) (figura 7).

Figura 7: Gráfico de correlação de Spearman entre as variáveis psicológicas e a umidade relativa nas rotinas de atividade e de plantão dos R2 no Setor da Imaginologia do Hospital de Clínicas da UNICAMP/Campinas: a. UR vs. estresse; b. UR vs. transtorno psiquiátrico; c. UR vs. qualidade do sono.

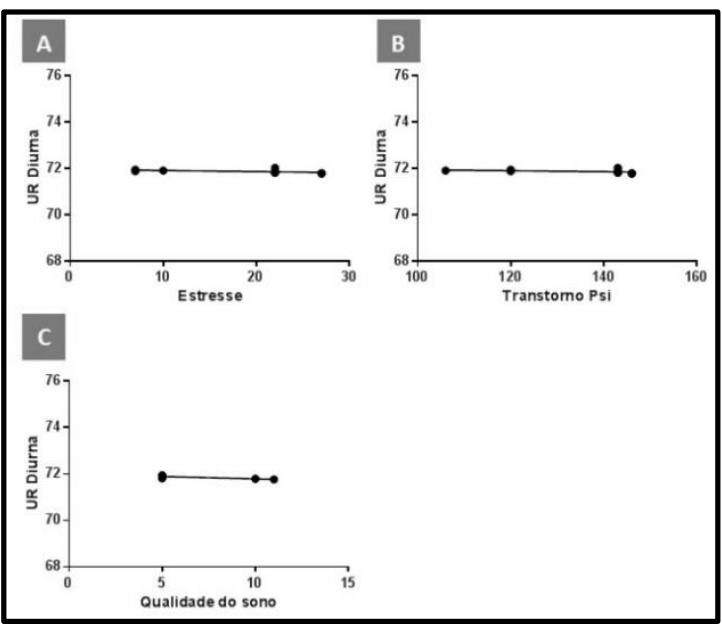

R3. Já os alunos do último ano, assim como os do primeiro, apresentaram relações para 2 condições ambientais: iluminância e temperatura. Para a iluminância: a. iluminância vs. depressão ( $\mathrm{r}$ de Spearman $=+0,0091)$; b. iluminância vs. transtorno psiquiátrico (r de Spearman $=+0,0091)$; $\mathrm{c}$. iluminância vs. estresse ( $\mathrm{r}$ de Spearman $=+0,0091$ ); d. iluminância vs. A-estado ( $\mathrm{r}$ de Spearman = $+0,0091)$; e. iluminância vs. sonolência (r de Spearman $=-<0,0001$ ) (figura 8). Para a temperatura: a. temperatura vs. transtorno psiquiátrico ( $\mathrm{r}$ de Spearman $=+0,0021)$; b. temperatura vs. qualidade do sono (r de Spearman =-<0,0001); c. temperatura vs. depressão (r de Spearman = -0,0476); $\mathrm{d}$. temperatura vs. estresse ( $\mathrm{r}$ de Spearman $=-0,0476$ ); e. temperatura vs. A-estado ( $\mathrm{r}$ de Spearman = 0,0476 ); f. temperatura vs. qualidade do sono ( $\mathrm{r}$ de Spearman $=-<0,0001$ ) (figura 9).

Figura 8: Gráfico de correlação de Spearman entre as variáveis psicológicas e a iluminância na rotina de atividade dos R3 no Setor da Imaginologia do Hospital de Clínicas da UNICAMP/Campinas: a. iluminância vs. depressão; b. iluminância vs. transtorno psiquiátrico; c. iluminância vs. estresse; d. iluminância vs. A-estado; e. iluminância vs. sonolência.

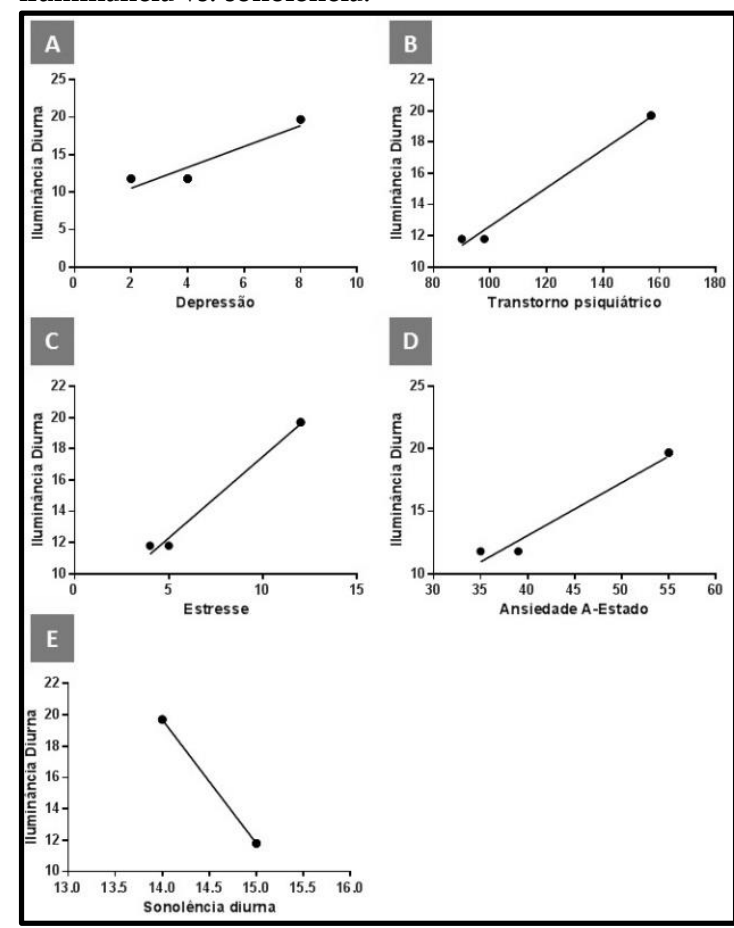

Figura 9: Gráfico de correlação de Spearman entre as variáveis psicológicas e a temperatura nas rotinas de atividade e plantão dos R3 no Setor da Imaginologia do Hospital de Clínicas da UNICAMP/Campinas: a. temperatura vs. transtorno psiquiátrico; b. temperatura vs. qualidade do sono; c. temperatura vs. depressão; $d$. temperatura vs. estresse; e. temperatura vs. A-estado; f. temperatura vs. qualidade do sono.

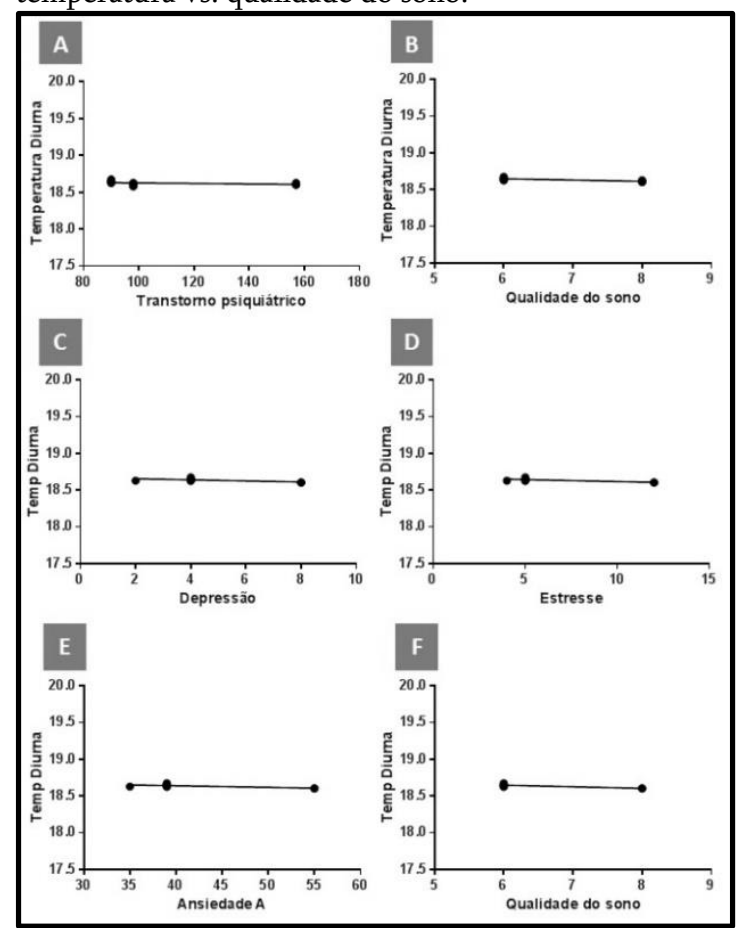




\section{Discussão}

Os ambientes não demonstraram integração entre os conceitos de conforto ambiental, bem-estar e estética espacial. Tal falha foi percebida pelo grau de cobrança e percepção espacial entre os médicos residentes. Os $\mathrm{R} 1$ foram os mais críticos, seguidos dos R2 e R3. Os médicos residentes do primeiro ano expuseram problemas advindos do(a): ruído e sua constância; iluminação com ofuscamento, presença de sombras na estação de trabalho, falta de uniformidade do sistema de iluminação e diferenciação de zonas de atividades dentro dos ambientes; espaço sem adequada distribuição do mobiliário, prejudicando a execução de tarefas. Os R2 reforçaram a existência e constância do ruído, bem como seu alcance no dormitório. A iluminação, contudo, caminhou entre a existência de sombras no plano de trabalho e a falta de uniformidade. No item de espaço e mobiliário, o único tópico que gerou incômodo foi a agradabilidade visual do setor. Já os R3 mostraram-se menos incomodados com o ambiente em si, ressaltando itens específicos, resultantes de uma vivência maior no ambiente e conhecedores das burocracias e carências locais. Eles perceberam e comprovaram a existência do ruído, a presença de sombras na estação de trabalho e a falta de uniformidade no sistema luminotécnico, ao mesmo tempo em que reconheciam as deficiências próprias do setor em um hospital universitário. Constatando-se que o desconforto ambiental sentido decresce à medida que o ambiente é vivenciado e suas falhas reconhecidas com o amadurecimento pessoal e profissional no local de residência médica, demonstrando as correlações obtidas anteriormente.

Frente à percepção ambiental obtida constatou-se correlação positiva entre os 03 grupos de voluntários: à medida que crescia a percepção positiva do ambiente para os R3, aumentada também as dos R2 e R1. Contudo, associação negativa entre percepção ambiental dos grupos R1 e R2 com a iluminância do setor: quanto menor os índices de iluminância, maiores as percepções ambientais positivas, comprovando a preferência pela quantidade presente da iluminância in loco devido a sua necessidade para a realização das atividades no setor, apesar dos R1 estranharem tal condição no início da residência médica (figura 10).
Figura 10: Síntese da relação entre percepção ambiental dos médicos residentes do Setor da Imaginologia do Hospital de Clínicas da UNICAMP/Campinas e as condições ambientais aferidas.

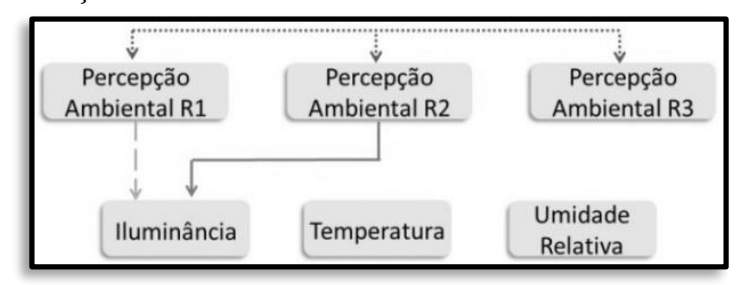

Ao analisar os resultados das variáveis emocionais por grupo, constatou-se que os médicos residentes R2 apresentaram dados diferenciados frente aos demais grupos. Os R2 alcançaram seja aproximando, igualando ou ultrapassando as pontuações ditas como limites para as variáveis: depressão, estresse, transtorno psiquiátrico, ansiedade, sonolência diurna e qualidade do sono. Os R1 trouxeram pontuações iguais ou acima no estresse (fase de alarme), ansiedade (Estado), sonolência diurna e qualidade do sono, com presença significativa de desenvolvimento de possíveis transtornos psiquiátricos dentro desta população. Quando correlacionados à percepção ambiental averiguou-se que ao cobrar demasiadamente o espaço de trabalho e unindo-se à sensação de impotência por não serem capazes de proverem melhorias no espaço daquele que o hospital objeto de desejo para a residência médica, o desconforto com as condições ambientais prevaleceu, consagrando o ambiente construído como fonte estressora juntamente com sentimentos diversos como a expectativa pela nova etapa de vida, insegurança, cobranças pessoais e mudanças (de cidade, de casa, de amigos, dentre outros). Os R3 obtiveram pontuações iguais ou acima da limítrofe, mas menor que a dos R2, para estresse e ansiedade (A-Estado). Isto demonstrou o desenvolvimento de quadro de estresse para a fase de resistência nos R3, além de comportamento ansioso e da presença constante de alguns sintomas psicossomáticos, mas ainda assim com melhores condições de saúde e bem-estar do que os outros 02 grupos. $\mathrm{O}$ amadurecimento pessoal e profissional, a vivência no setor e a habilidade de filtrar ameaças auxiliaram a criar novos registros de feedback emocional, remodelando os antigos e reestruturando psíquicoemocionalmente os médicos residentes, tornando-os capazes de se ajustarem ao meio e às condições 
impostas, favorecendo a homeostasia.

A análise dos resultados permitiu a discussão dos questionamentos inicialmente feitos. As condições ambientais comportaram análises frente a 03 realidades encontradas: aferição abaixo das normas regulamentadoras, aferição dentro dos limites máximos e mínimos e aferição acima dos valores preconizados. Os baixos índices aferidos nas condições ambientais (iluminação, temperatura e umidade relativa), em termos quantitativos, não contribuíram para o aumento do estresse, ansiedade e depressão nos médicos residentes do Setor da Imaginologia do HC/Campinas; assim como não causaram as sensações comumente detectadas de apatia e medo, por exemplo, por ser uma necessidade inerente à atividade desenvolvida no setor menores valores de iluminância e temperatura. Os altos índices igualmente não influenciaram os aspectos psicológicos por não se encontrarem muito acima dos valores tidos como limítrofes máximos para os ambientes estudados. Desta forma, as variáveis emocionais não foram induzidas e os valores aferidos não foram considerados como ameaça pelo organismo dos voluntários, e neste sentido a homeostasia esteve presente.

A qualidade apresentada do ambiente construído do Setor da Imaginologia do HC/Campinas influenciou até determinado ponto as variáveis emocionais dos médicos residentes. As condições ambientais dos sistemas de iluminação e térmica, e suas respectivas humanizações, provocaram desconfortos diversos que diminuíram à medida que a vivência no espaço era maior como os sentimentos de impotência, decepção pela alta expectativa por se encontrar em uma residência médica em um hospital de renome e não ter as condições de trabalho adequadas ao esperado. Esta mesma qualidade, nas atuais condições ambientais, contribuiu para a alteração da qualidade de sono dos médicos residentes especialmente dos R1 e R2 tendo em vista o desconforto provocado por aquela somado seja aos transtornos psicológicos seja pela rotina sobrecarregada. Com relação à quantidade, esta não foi responsável pela desordem no sono.

Desta forma, para o setor estudado, as condições ambientais que promoveriam bem-estar e satisfação de uso do ambiente de trabalho foram aqueles qualificados como baixos no caso da iluminância e amenas para as temperaturas visando a atividade de laudear. Maiores valores de iluminância no plano de trabalho só eram requeridas quando da necessidade de estudos nas salas de laudo por meio de material impresso. Devido a não integração dos ambientes com conceitos de conforto ambiental, bem-estar e estética espacial, a percepção ambiental se deu de forma fragmentada, pendendo negativamente para o caráter da qualidade. A falta de humanização e cuidados ambientais desfavoreceu a cognição espacial por parte dos usuários, especialmente entre os R1, seguidos dos R2 e R3. Constatando-se que para as condições encontradas no Setor da Imaginologia do HC/Campinas, a percepção ambiental, positiva ou negativa, se deu de acordo com a vivência e amadurecimento pessoal e profissional no ambiente, e a isto se tem os níveis de residência médica.

\section{Conclusões}

Com o desenvolvimento de novos procedimentos e tecnologias para diagnósticos, a Imaginologia passou a ter maior responsabilidade no diagnóstico precoce de doenças. O preparo de um profissional dessa área exige cuidados que vão além do conhecimento repassados em salas de aula.

A competitividade na área de medicina é marcada desde o vestibular até o momento da escolha da especialização e consequente entrada na residência médica. $\mathrm{O}$ desgaste emocional acumulado por anos junta-se à adaptação ao hospital da residência médica, a novas responsabilidades, rotinas, estabelecimento de vínculos socioafetivos - o que por vezes não é bem recepcionado pelos veteranos e a competição já instaurada -, dentre outros. Além disto, há por vezes o desencontro entre as realidades idealizada e experimentada frente à especialização escolhida, provocando por vezes o desejo de abandono do curso e/ou crise de identidade. Uma dessas frustrações está no ambiente físico hospitalar com condições ambientais deficientes que dificultam a realização adequada do trabalho previsto, mas que mesmo assim é esperado que os recém-admitidos executem suas tarefas satisfatoriamente independente das condições que lhes são dadas.

Cresce a preocupação com o ambiente hospitalar além do paciente. Seus espaços também devem 
alcançar a esfera dos funcionários da saúde de acordo com as atividades previstas. Para a Imaginologia não basta apenas projetar espaços que caibam máquinas como as de ressonância magnética ou tomografia, devem-se conhecer o que os funcionários da saúde realmente fazem nesse setor, os tipos de atividades que precisam ser facilitados, o tipo de ambiente mais indicado para a realização daquelas, dentre outros. $\mathrm{O}$ espaço de trabalho não deve envolver somente questões de custos ou design do projeto, mas também o cotidiano, produtividade, flexibilidade, cultura e bem-estar de seus usuários. Seu objetivo é dar suporte no exercício das atividades aos seus usuários e o projeto incentiva isto, bem como a interatividade dos funcionários, por exemplo. A produtividade decorrente daquele objetivo parte do princípio de que a empresa fornece um ambiente adequado para tal, respeitando normas básicas como as de ergonomia e conforto ambiental, bem como as necessidades psicológicas e comportamentais, evitando que o ambiente agrida o indivíduo, pois cada ambiente é compreendido, observado e julgado de distintas formas por seus usuários (HALL, 2005). No caso da residência médica em Imaginologia, a exigência mínima para a produtividade é a concentração na atividade de laudear, exigindo um ambiente livre de distrações e ruídos desnecessários, por exemplo. Contudo, mesmo espaços com certa privacidade social e visual necessitam de um projeto também criativo, favorecendo ambientes que estimulem a troca de ideias, a liberdade do pensar e o modo de agir dos usuários. A aparência e a atmosfera do ambiente de trabalho têm forte impacto naqueles e isto se torna importante quando a faculdade é vista como um local idealizado, onde o desejo de ser médico especialista será satisfeito.

Estudos tendo como amostra principal os médicos residentes são poucos, mas aqueles feitos com outras tipologias populacionais vêm demonstrando importantes resultados que auxiliam a compreensão da saúde psicológica de indivíduos em diversas situações de trabalho. Contudo, se faz necessário ainda estudar, mediante pesquisas completares, o tratamento qualitativo e quantitativo das variáveis ambientais para cada tipologia de atividade correlacionando-as para além das questões usualmente tratadas pela arquitetura: respostas psicológicas humanas. Estes estudos auxiliarão a reorganizar novas e específicas diretrizes que incorporem ambientes mais salubres.

\section{Agradecimentos}

Agradecemos a Fundação de Amparo à Pesquisa do Estado de São Paulo (FAPESP) pelo apoio financeiro.

\section{Referências}

ASSOCIAÇÃO BRASILEIRA DE NORMAS TÉCNICAS (ABNT). NBR 9050 - Acessibilidade a edificações, mobiliário, espaços e equipamentos urbanos. Rio de Janeiro: ABNT, 2005.

ASSOCIAÇÃO BRASILEIRA DE NORMAS TÉCNICAS (ABNT). NBR ISO/CIE 8995:1 Iluminação de ambientes de trabalho Parte 1: Interior. Rio de Janeiro: ABNT, 2013.

ASSOCIAÇÃO BRASILEIRA DE NORMAS TÉCNICAS (ABNT). NR 17 - Ergonomia. Rio de Janeiro: ABNT, 2007.

BAKER, N.; STEEMERS, K. Daylight Design of Buildings: A Handbook for Architects and Engineers. EUA: Routledge, 2002.

BATIZ, E.C.; GOEDERT, J.; MORSCH, J.J.; JUNIOR, P.K.; VENSKE, R. Avaliação do conforto térmico no aprendizado: estudo de caso sobre influência na atenção e memória. Revista Produção 19: 477-488, 2009.

BECK A.T.; STEER, R.A.; BROWN, G.K. Manual for the Beck Depression Inventory-II. EUA: Psychological Corporation, 1996.

BECK, A. T. Depression: Causes and Treatment. Philadelphia: University of Pennsylvania Press, 2006.

BOYCE, P. Human factors in lighting. 2aed. Londres: Taylor \& Francis, 2003.

BRASIL. Ministério da Saúde. Manual do Residente. Brasília: Ministério da Saúde, 2002. Disponível em $<$ http://portal.mec.gov.br/index.php?option=com_c ontent\&id=12263\&Itemid=507 $>$. Acesso em mai, 2013.

BREVIGLIERO, E.; POSSEBON, J.; SPINELLI, R. Higiene ocupacional: agentes biológicos, químicos e físicos. 5a ed. São Paulo: Editora SENAC São Paulo, 2006. 
BUYSSE, D.J.; REYNOLDS III, C.F.; MONK, T.H.; BERMAN, S.R.; KUPFER, D.J. The Pittsburgh Sleep Quality Index: a new instrument for psychiatric practice and research. Psychiatric Research 28: 193213, 1989.

CARLSON, N.R. Fisiologia do comportamento. 7a ed. Barueri/SP: Editora Manole, 2002.

FANGER, P.O. Thermal comfort. New York: McGraw-Hill Book Company, 1970.

GOLDBERG, D.P. The detection of psychiatric illness by questionnaire: a technique for the identification and assessment of non-psychotic psychiatric illness. Trad. Luiz Pasquali, Valdiney Veloso Gouveia, Wagner Bandeira Andriola, Fabio jesus Miranda, Andre Luiz Moraes Ramos. São Paulo: Laboratório em Avaliação e Medida LABPAM/ Editora Casa do Psicológo, 1996.

Graphpad Software Inc. GraphPad Prism v.6.0. California: Graphpad Software Inc., 2014.

GUZOWSKI, M. Daylighting for sustainable design. New York: McGraw Hill, 1999.

IIDA, I. Ergonomia: projeto e produção. 2a ed. São Paulo: Editora Blucher, 2005.

International Business Machines (IBM). Statistical Package for Social Science - SPSS Statistics. Versão 22.0. Chicago: IBM, 2013.

International Organization for Standardization (ISO) ISO 10551 - Ergonomics of the thermal environment - Assessment of the influence of the thermal environment using subjective judgement scales. Genebra: ISO, 1995.

International Organization for Standardization (ISO) ISO 7726 - Thermal environments: Instruments and methods for measuring physical quantities. Genebra: ISO, 1998.

JOHNS, M.W. A new method for measuring daytime sleepiness: the Epworth Sleepiness Scale. Journal of Sleep 14: 540-545, 1991.

LIPP, M.N. ISSL - Inventário de Sintomas de Stress para Adultos de Lipp. 3a ed. São Paulo: Editora Casa do Psicólogo, 2005.

MICROSOFT. Microsoft Excel 2010. EUA:
Microsoft Corporation, 2010.

NELSON, D.; AYLOR, B.; NELSON, R. Development of a questionnaire to examine worker risk perception of noise and use of hearing protection devices. American Industrial Hygiene Conference \& Exposition (AIHce), Toronto, 1999. Anais. Toronto: AIHce, 1999.

RABINOWITZ, P. Noise-induced hearing loss. American Family Physician 61: 2749-2756, 2000.

RUNDMO, T. Associations between risk perception and safety. Safety Science 24: 197-209, 1996.

SASSI, P. Strategies for sustainable architecture. New York: Taylor\&Francis, 2006

SPIELBERGER, C.D.; GORSUCH, R.L.; LUSHENE, R.E. IDATE - Inventário de Ansiedade de TraçoEstado. Trad. Angela M. B. Biaggio e Luiz Natalicio. 2a ed. Rio de Janeiro: Centro Editor de Psicologia Aplicada, 2003.

ZUMTOBEL ELI-LENI Calculator.Versão 3.2.0. Austria: Zumtobel Lighting, 2010.

ZUMTOBEL. The lighting handbook. Austria: Zumtobel Lighting, 2008. 